\title{
Community health workers at the dawn of a new era: 11. CHWs leading the way to "Health for All"
}

Henry B. Perry ${ }^{1 *} \mathbb{0}$, Mushtaque Chowdhury² ${ }^{2}$ Miriam Were ${ }^{3}$, Karen LeBan $^{4}$, Lauren Crigler $^{5}$, Simon Lewin ${ }^{6}$,

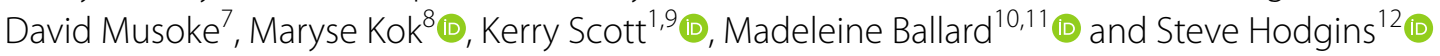

\begin{abstract}
Background: This is the concluding paper of our 11-paper supplement, "Community health workers at the dawn of a new era".

Methods: We relied on our collective experience, an extensive body of literature about community health workers (CHWs), and the other papers in this supplement to identify the most pressing challenges facing CHW programmes and approaches for strengthening CHW programmes.

Results: CHWs are increasingly being recognized as a critical resource for achieving national and global health goals. These goals include achieving the health-related Sustainable Development Goals of Universal Health Coverage, ending preventable child and maternal deaths, and making a major contribution to the control of HIV, tuberculosis, malaria, and noncommunicable diseases. CHWs can also play a critical role in responding to current and future pandemics. For these reasons, we argue that CHWs are now at the dawn of a new era. While CHW programmes have long been an underfunded afterthought, they are now front and centre as the emerging foundation of health systems. Despite this increased attention, CHW programmes continue to face the same pressing challenges: inadequate financing, lack of supplies and commodities, low compensation of CHWs, and inadequate supervision. We outline approaches for strengthening CHW programmes, arguing that their enormous potential will only be realized when investment and health system support matches rhetoric. Rigorous monitoring, evaluation, and implementation research are also needed to enable CHW programmes to continuously improve their quality and effectiveness.
\end{abstract}

Conclusion: A marked increase in sustainable funding for $\mathrm{CHW}$ programmes is needed, and this will require increased domestic political support for prioritizing CHW programmes as economies grow and additional healthrelated funding becomes available. The paradigm shift called for here will be an important step in accelerating progress in achieving current global health goals and in reaching the goal of Health for All.

Keywords: Community health workers, Community health worker programmes, Lay health workers, Communitybased primary healthcare, Primary healthcare, Sustainable development goals, Ending preventable child and maternal deaths, Universal Health Coverage

\footnotetext{
*Correspondence: hperry2@jhu.edu

${ }^{1}$ Department of International Health, Johns Hopkins Bloomberg School of Public Health, Baltimore, MD, USA
}

Full list of author information is available at the end of the article

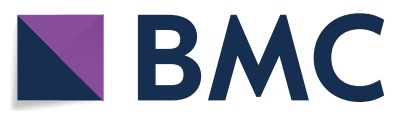

(c) The Author(s) 2021. Open Access This article is licensed under a Creative Commons Attribution 4.0 International License, which permits use, sharing, adaptation, distribution and reproduction in any medium or format, as long as you give appropriate credit to the original author(s) and the source, provide a link to the Creative Commons licence, and indicate if changes were made. The images or other third party material in this article are included in the article's Creative Commons licence, unless indicated otherwise in a credit line to the material. If material is not included in the article's Creative Commons licence and your intended use is not permitted by statutory regulation or exceeds the permitted use, you will need to obtain permission directly from the copyright holder. To view a copy of this licence, visit http://creativecommons.org/licenses/by/4.0/. The Creative Commons Public Domain Dedication waiver (http://creativeco mmons.org/publicdomain/zero/1.0/) applies to the data made available in this article, unless otherwise stated in a credit line to the data. 


\section{Key message box 1: Summary}

\section{Key findings}

- National community health worker (CHW) programmes face many challenges which prevent them from reaching their full potential.

- The lack of national political support and sustainable funding (from both domestic and donor sources) for national CHW programmes is perhaps the most critical challenge facing these programmes.

- Other key challenges these programmes face include provision of programme supplies and commodities, compensation of CHWs, and supervision.

\section{Key implications}

- Developing, expanding, and strengthening national $\mathrm{CHW}$ programmes represent promising approaches to accelerating progress in achieving the global health goals of Universal Health Coverage, ending preventable child and maternal deaths, and achieving "Health for All".

- By building on current evidence and best practices, and investing in rigorous monitoring, evaluation, and implementation research, national CHW programmes have the potential to lead the way in reaching "Health for All".

\section{Background}

This is the 11th and final paper in our series, "Community health workers at the dawn of a new era". The first paper provides an introduction to the current status of national $\mathrm{CHW}$ programmes, their role within the peripheral health system and the community health system, and some of the long-standing tensions related to the identity and orientation of CHWs in national health systems [1]. The second and third papers address coordination, planning, partnerships, and governance-all critical issues for national $\mathrm{CHW}$ programmes, which intersect with so many components of society and government and are themselves complex entities [2,3]. As these programmes become stronger and more embedded within health systems rather than, as in many countries, stand-alone projects mostly funded by external donors, coordination, planning, partnerships, and governance gradually take on increasing importance. Long-term financing of $\mathrm{CHW}$ programmes, as discussed in the fourth paper [4], is a critically important issue as national $\mathrm{CHW}$ programmes gain momentum. Making a compelling case based on the expected return on investment both for improving population health and for promoting socioeconomic development will be critical for generating the political will to ensure stronger long-term domestic funding for these programmes as well as more immediate donor funding and longer-term support from donors as well.

The fifth paper addresses roles and tasks that CHWs perform-an increasingly complex issue as the evidence grows regarding the range of functions that trained and supported CHWs are capable of fulfilling [5]. There is a steady but persistently increasing professionalization of $\mathrm{CHW}$ roles. There is also an emerging dual cadre of CHWs in which professionalized CHWs are supervising lower tiers of CHWs, who are often volunteers responsible for a small number of households. These dynamics along with the changing priorities of countries as they pass through the epidemiologic transition means that the roles and tasks of CHWs will continue to evolve, as the experience with the national CHW programme in Brazil demonstrates.

The training of CHWs [6] (the sixth paper) along with their supervision [7] (the seventh paper) and incentives/ reimbursement [8] (the eighth paper) are all elements of national CHW programmes that influence programme performance. New approaches that more effectively meet the needs of CHWs are being tried in many programmes. There is growing recognition of the need for fair remuneration for full- and part-time CHWs. A role also remains for voluntary $\mathrm{CHWs}$, who can make important contributions as long as they are not be expected to work more than a few hours per week or perform the role of regular full- or part-time workers.

The need for national CHW programmes to be embedded in both communities and health systems is highlighted in the ninth paper [9]. The tenth paper [10] focuses on the performance of CHWs and CHW programmes and approaches to assessing performance. A comprehensive approach is needed since the effectiveness of the whole programme is dependent on how well each component of the system is functioning; addressing one component without consideration of the other components is not likely to improve programme effectiveness. The paper highlights the importance of both human and technical components of performance. Table 1 contains the key messages and key implications from each of these 10 papers.

This series of papers builds on previous work of our writing team, most notably the widely used $2014 \mathrm{CHW}$ Reference Guide, which was intended to guide $\mathrm{CHW}$ programme managers and policy-makers in developing and strengthening $\mathrm{CHW}$ programmes at scale [11]. In 


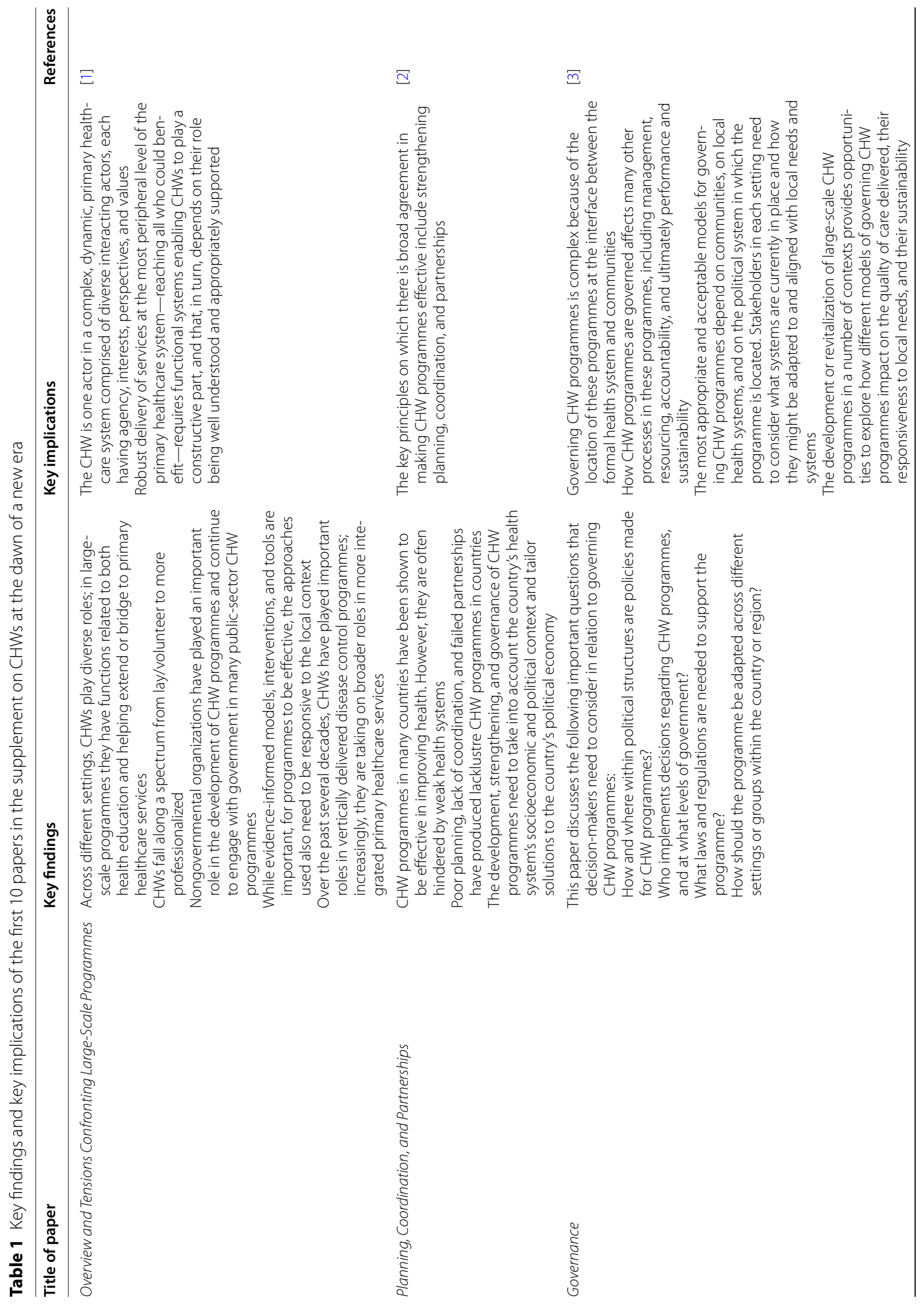




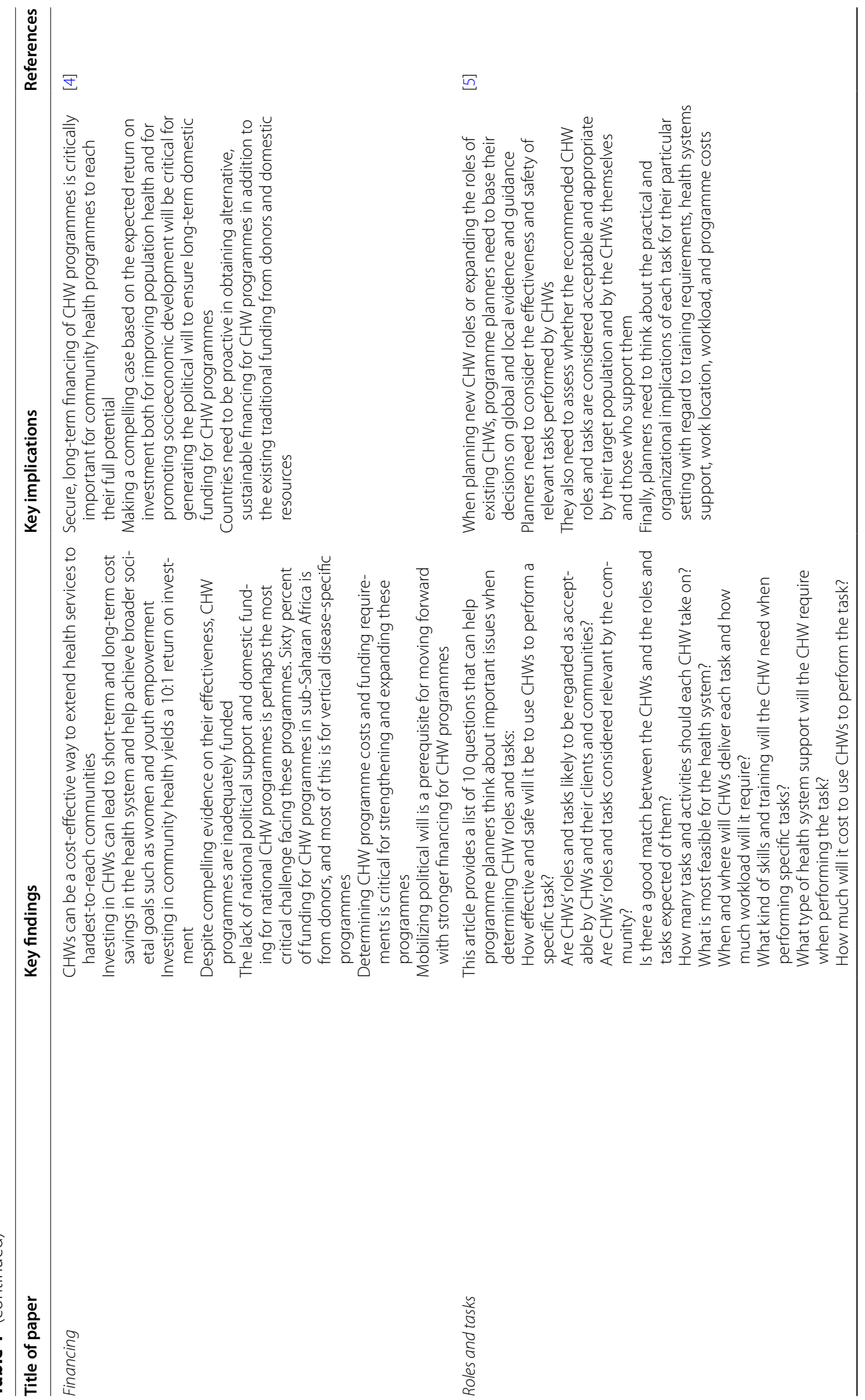




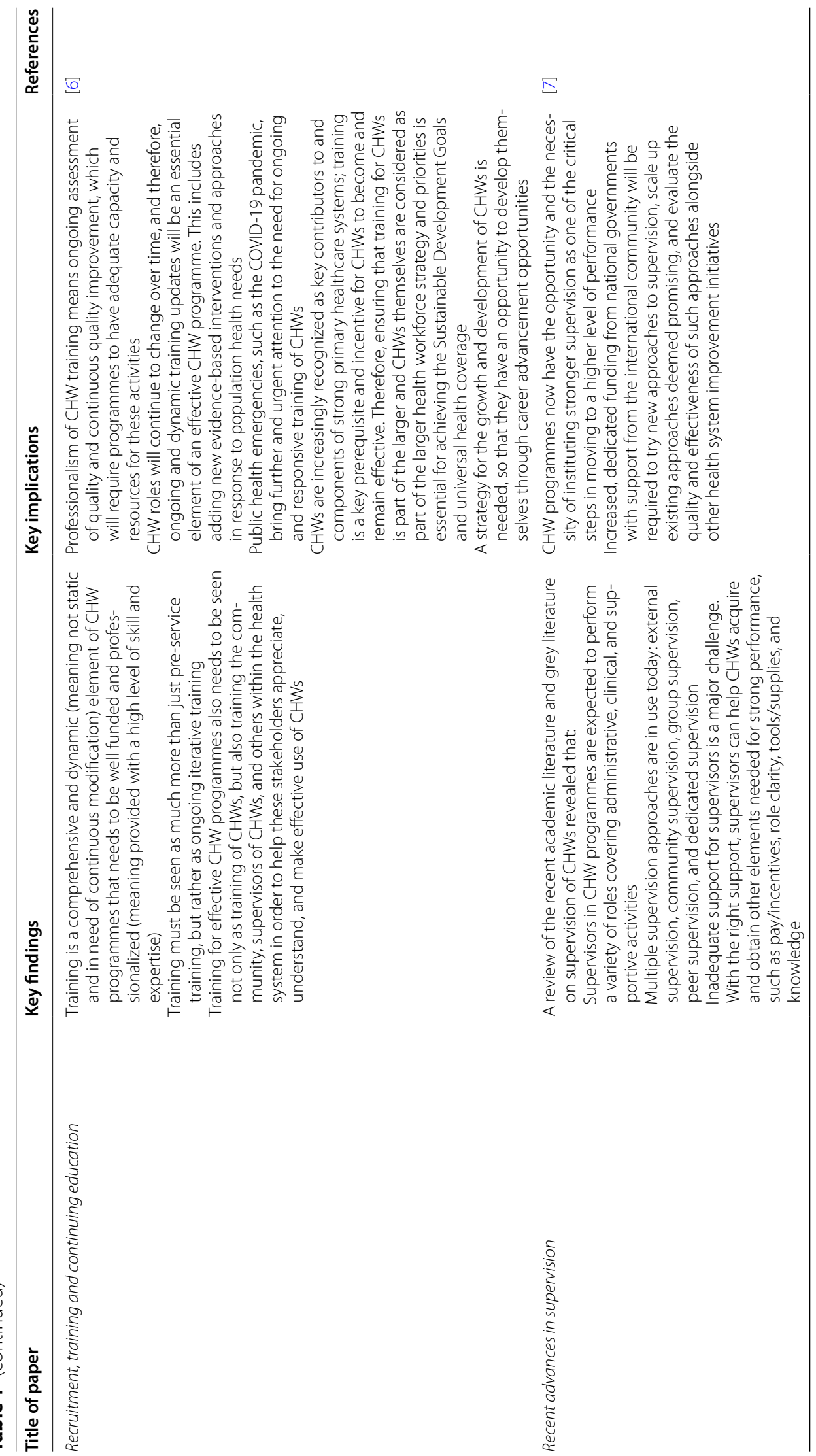




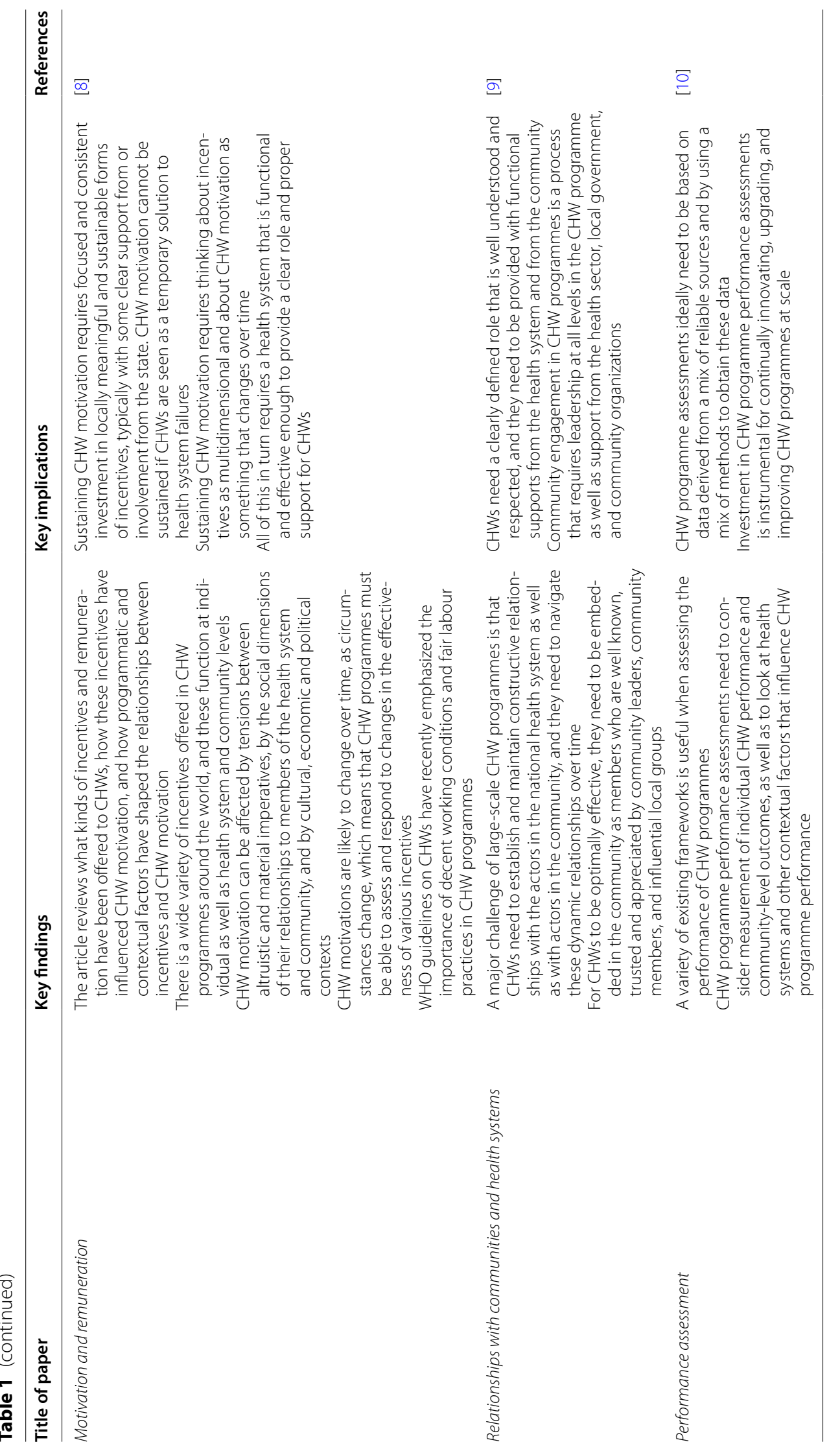


addition, we draw heavily on recently released World Health Organization (WHO) guidelines guidelines for $\mathrm{CHW}$ programmes [12] and a compendium of case studies of 29 national CHW programmes [13].

In this final paper, we seek to identify opportunities for building stronger $\mathrm{CHW}$ programmes and greater community engagement. We see this as a means for achieving global health goals and strengthening health systems throughout the world to reach their full potential and to achieve "Health for All", where health inequities both within and between countries are minimal, as envisioned at Alma-Ata more than four decades ago.

In 2018 the world celebrated the 40th anniversary of the 1978 Declaration of Alma-Ata and reaffirmed its basic principles, calling for a renewed global commitment to the goal of universal health coverage (UHC) through primary healthcare (PHC) as defined in the original Declaration [14]. In 2019, the United Nations General Assembly unanimously passed a resolution [15] stating that "measurable acceleration is urgently needed" to reach the health-related targets of the Sustainable Development Goals (SDGs) by 2030-namely UHC and ending preventable child and maternal deaths. Unless progress toward this goal accelerates, up to one third of the world's population will still remain underserved by 2030 [15].

Not since Halfdan Mahler was Director-General of WHO from 1973 to 1988 , has WHO had a leader as passionate about PHC and community health. Dr. Tedros Adhanom led the transformation of Ethiopia's health system from a focus on hospitals and urban populations to an emphasis on strong community-based PHC programmes in which vertical programmes were effectively delivered at the community level through a common PHC platform. As a result, Ethiopia became a global leader in attaining the Millennium Development Goals for maternal and child health, HIV/AIDS, malaria, and tuberculosis $[16,17]$ and in accelerating progress in achieving UHC [17].

Tedros Adhanom's leadership is now helping to guide WHO toward embracing more fully the goal of stronger PHC and community health programmes. And, for him, the platform of community-based service delivery by $\mathrm{CHWs}$ and engagement of communities as partners and resources are fundamental to the concept of PHC and community health [18]. As he said in his address to the World Health Assembly in 2019, "[T] here will be no UHC without PHC" [18]. Similarly, it is fair to say, particularly in resource-constrained, high-mortality settings, there can be no PHC without CHWs. CHWs need to be understood as the foundation of PHC as well as an increasingly important component of health systems in settings where delivery or equity gaps are present. The 2019 World Health Assembly resolution highlighted the importance of CHWs for achieving global public health goals [19] and called for the adoption of recently released WHO guidelines on health policy and system support to optimize CHW programmes [12].

CHW programmes are at a historical moment in which their contribution to health systems and population health improvement is increasingly being recognized as an integral part of health systems, particularly (but not exclusively) in low- and middle-income countries (LMICs), rather than continuing to be an underfunded afterthought. The growing recognition of the value of $\mathrm{CHW}$ programmes reflects the following key factors:

(1) Evidence of the effectiveness of adequately trained and supported CHWs in providing quality health services and improving population health continues to grow [13, 20-23]. This evidence indicates that the number of lives of mothers and their children that can be saved each year by increasing the population coverage of the evidence-based promotive, preventive, and curative interventions provided by CHWs is even greater than the number that can be saved by expanding facility-based services at PHC centres and hospitals (1.7 million versus 2.3 million) [21, 24], although of course both strategies must be pursued in tandem.

(2) Countries that have been making the strongest gains in population health outcomes have strong CHW programmes; Bangladesh, Brazil, Ethiopia, Nepal, and Rwanda are prominent examples [25].

(3) WHO has, for the first time, created a set of guidelines for optimizing the contribution of CHW programmes to health systems [12].

The COVID-19 pandemic has made very clear the need for health workers on the ground who can visit homes to provide education about COVID-19, assist in identifying cases and tracing contacts, linking cases to treatment, and supporting vaccination [26]. The result is that the pandemic has led to calls throughout the world for CHWs to receive the proper respect and status that they deserve, not to mention the personal protective equipment they need to safely carry out their duties [27]. For example, the pandemic has led to a call for the creation of a CHW cadre in the United Kingdom that would continue, for the foreseeable future, to link all households with a CHW who can assist in addressing health needs in the household [28]. Similar proposals are emerging in the United States [29, 30]. 
On a broader scale, we are in the midst of a process some are calling "the third global health transition" [31] or "a grand convergence" [32] - emerging from a demographic transition (from higher to lower death and birth rates) into an epidemiologic transition (from a high burden of maternal and child conditions and communicable diseases to noncommunicable diseases [NCDs]). The world's sights are shifting to achieving UHC, ending preventable child and maternal deaths, ending HIV/AIDS, controlling malaria and tuberculosis, controlling NCDs, and, most recently, to anticipating and responding to rapidly progressing epidemics and pandemics, which threaten health systems themselves. As the world's wealth, technology, knowledge, and skills increase, persistent health disparities and untimely deaths from readily preventable or treatable conditions become even more unjust and morally unacceptable. There are unprecedented new technologies, tools, and programmatic approaches which offer the prospect of increasing the effectiveness of CHWs, provided they are giving appropriate training and support.

\section{Current challenges facing national $\mathrm{CHW}$ programmes}

\section{Key message box 2}

In a recently produced compendium of case studies of national $\mathrm{CHW}$ programmes, the most commonly cited challenges were (1) inadequate programme financing, (2) interruptions in the supply chain for basic supplies, commodities, and medicines, (3) inadequate remuneration of CHWs, and (4) inadequate or poor-quality supervision.

A recently published set of case studies [13] provides insights into the structures, achievements, and challenges faced by national $\mathrm{CHW}$ programmes (Box 1). In each of the case studies, the authors describe the major challenges that these programmes face. The findings, summarized in Table 2, provide a realistic, grounded view of the constraints under which such programmes are currently functioning. Each national CHW programme faces many challenges of all sorts. What Table 2 provides is a listing of those that were considered by the authors of the case studies to be the most pressing challenges for that programme. Therefore, it does not provide an all-encompassing list of all the challenges these programmes face. The four most frequently seen challenges concern the supply chain for key programme commodities used by CHWs, programme financing, $\mathrm{CHW}$ compensation, and supervision. Each of these challenges was found to be a prominent issue for over half of the programmes documented in this set of case studies.

\section{Box 1. Contents of the book, Health for the People: National Community Health Worker Program from Afghanistan to Zimbabwe [13]}

The book contains 29 case studies of national CHW programmes from Afghanistan, Bangladesh, Brazil, Ethiopia, Ghana, Guatemala, India, Indonesia, Iran, Kenya, Liberia, Madagascar, Malawi, Mozambique, Myanmar, Nepal, Niger, Nigeria, Pakistan, Rwanda, Sierra Leone, South Africa, Tanzania, Thailand, Uganda, Zambia, and Zimbabwe. Each case study has at least one author who has personal in-country experience with the programme described, and each follows a common format to facilitate comparisons across cases. The studies look at a mix of CHW types, from the more professionalized end of the spectrum to less formalized volunteer $\mathrm{CHW}$ programmes. The programmes described are drawn from diverse regions and from both low-income and middleincome countries.

\section{How can national CHW programmes be strengthened?}

\section{Key message box 3}

The strengthening of national $\mathrm{CHW}$ programmes will require building stronger leadership among those who understand the importance of $\mathrm{CHW}$ programmes and are passionate about strengthening these programmes. These people, in turn, can help to build national political support for expanding government support for these programmes. Increased donor support is needed, as are investments in rigorous programme monitoring, evaluation, and implementation research to enable national $\mathrm{CHW}$ programmes to reach their full potential.

Drawing on the papers in the series, we discuss below key questions related to strengthening $\mathrm{CHW}$ programmes and outline our thoughts on how these might be addressed. These suggestions are not intended to be definitive, and we would welcome further ideas and discussion. As we note below, innovations should be linked with ongoing monitoring and evaluation using appropriate methods.

How can we foster leadership and passion for $\mathrm{CHW}$ programmes globally and locally?

- Amplify CHW voices by identifying and supporting CHWs to participate in meetings where they share 
Table 2 Challenges cited by authors of 29 case studies of national CHW programmes [13]

\begin{tabular}{|c|c|c|}
\hline Type of challenge & $\begin{array}{l}\text { Number of national programmes for } \\
\text { which this challenge was mentioned }\end{array}$ & $\begin{array}{l}\text { Countries in which they challenge was mentioned and } \\
\text { name of } \mathrm{CHW} \text { cadre involved }\end{array}$ \\
\hline Lack of supplies and commodities & 20 & $\begin{array}{l}\text { Ethiopia (HEW, WDA); India (ANM, AWW, ASHA, VHG); } \\
\text { Kenya (CHW); Liberia (CHA, CHSS); Malawi (CHW); } \\
\text { Mozambique (APE); Niger (ASC, RV); Rwanda (Binome, } \\
\text { ASM); Sierra Leone (CHW); South Africa (WBPHCOT); } \\
\text { Zambia (CHA, CBV); Zimbabwe (VHW) }\end{array}$ \\
\hline Inadequate, unstable, or unsustainable financing & 20 & $\begin{array}{l}\text { Brazil (ASC Agent); Ghana (CHO, CHV); Indonesia (Kader); } \\
\text { Liberia (CHA, CHSS); Malawi (CHW); Mozambique (APE); } \\
\text { Myanmar (AMW, CHW, MV, TBV, TBA), Pakistan (LHW); } \\
\text { Rwanda (Binome, ASM); Sierra Leone (CHW); South Africa } \\
\text { (WBPHCOT); Tanzania (CHW); Zimbabwe (VHW) }\end{array}$ \\
\hline Low compensation of CHWs & 17 & $\begin{array}{l}\text { Brazil (CHW); Ghana (CHO, CHV); India (ANM, AWW, ASHA, } \\
\text { VHG); Iran (B, MS), Kenya (CHV); Malawi (CHW); Mozam- } \\
\text { bique (APE); Pakistan (LHW); South Africa (WBPHCOT), } \\
\text { Zambia (CHW, CBV); Zimbabwe (VHW) }\end{array}$ \\
\hline Inadequate supervision & 15 & $\begin{array}{l}\text { Brazil (ASC-agent); Ethiopia (HEW, WDA); India (ANM, } \\
\text { AWW, SAHA, VHG); Mozambique (APE); Niger (ASC, } \\
\text { RV); Rwanda (Binome; ASM); South Africa (WBPHCOT); } \\
\text { Zambia (CH-assistant, CBV) }\end{array}$ \\
\hline Management challenges & 11 & $\begin{array}{l}\text { Brazil (ASC-agent); Ghana (CHO, CHV). Iran (B, MS); Kenya } \\
\text { (CHV); Malawi (CHW); Nigeria (CHW, CHIPS, CDD); } \\
\text { Tanzania (CHW) }\end{array}$ \\
\hline Overall shortage of human resources & 10 & $\begin{array}{l}\text { Indonesia (Kader); Liberia (CHA, CHSS); Kenya (CHV), } \\
\text { Madagascar (AC, ACN); Malawi (CHW); Niger (ASC, RV), } \\
\text { Pakistan (LHW) }\end{array}$ \\
\hline Weak linkage with the formal health system & 10 & $\begin{array}{c}\text { Brazil (ASC-agent); Ethiopia (HEW, WDA); Kenya (CHW), } \\
\text { Malawi (CHW). Myanmar (AMW, CHW, MV, TBV, TBA) }\end{array}$ \\
\hline Unavailability of health facilities & 9 & $\begin{array}{l}\text { India (ANM, AWW, ASHA, VHG); Iran (B, MS); Malawi (CHW), } \\
\text { Niger (ASC, RV) }\end{array}$ \\
\hline Deficient training & 8 & $\begin{array}{l}\text { Brazil (ASC-agent); Ethiopia (HEW, WDA); India (ANM, } \\
\text { AWW, ASHA, VHG); Mozambique (APE) }\end{array}$ \\
\hline Low level of community involvement & 7 & $\begin{array}{l}\text { India (ANM, AWW, ASHA, VHG); Thailand (VHV); Kenya } \\
\text { (CHV); Malawi (CHW) }\end{array}$ \\
\hline Inappropriate workload & 7 & $\begin{array}{l}\text { Ethiopia (HEW, WDA); Rwanda (Binome, ASM); Malawi } \\
(\mathrm{CHW}) ; \text { Zambia (CHA, CBV) }\end{array}$ \\
\hline Role constraints & 6 & $\begin{array}{l}\text { Nepal (FCHV); Nigeria (CHEW, CHIP, CDD, CHA); Zambia } \\
\quad(\mathrm{CHA}, \mathrm{CBV})\end{array}$ \\
\hline Limited career progression & 6 & $\begin{array}{l}\text { Bangladesh (FWA, HA, CHCP); Ethiopia (HEW, WDA); } \\
\text { Mozambique (APE) }\end{array}$ \\
\hline Fragmented (vertical) programming & 5 & Myanmar (AMW, CHW, MV, TBV, TBA) \\
\hline Low quality of services & 5 & $\begin{array}{l}\text { Bangladesh (FWA, HA, CHCP), Kenya (CHV); Tanzania } \\
(\mathrm{CHW})\end{array}$ \\
\hline Violence and sexual harassment against CHWs & 4 & India (ANM, AWW, ASHA, VHG) \\
\hline Increased health needs & 4 & Bangladesh (SS, SK); Madagascar (AC, ACN) \\
\hline Discrimination & 4 & Bangladesh (SS, SK); Iran (B, MS) \\
\hline Programme inefficiencies & 4 & Afghanistan (CHW); Ethiopia (HEW, WDA), Kenya (CHV) \\
\hline Lack of political support for the CHW programme & 3 & Indonesia (Kader), Kenya (CHV); South Africa (WBPHCOT) \\
\hline Limited educational background of CHWs & 2 & South Africa (WBPHCOT); Thailand (VHV) \\
\hline High turnover of $\mathrm{CHWs}$ & 2 & Brazil (CH-agent); Kenya (CHV) \\
\hline
\end{tabular}

AWW: aganwadi worker; AC: agent communautaire; ACN: agent communautaire nutritional; AMW: auxiliary midwife; ANM: auxiliary nurse midwife; APE: agent polivalente elementares; ASC: agent de santé communautaire; ASHA: accredited social health activist; ASM: agent de santé maternelle; B: behvarzs; CBV: communitybased volunteer; CDD: community-directed distributor; $\mathrm{CHA}$ : community health agent; $\mathrm{CHCP}$ : community healthcare provider; $\mathrm{CHEW}$ : community health extension worker; CHIP: community health influencer and promoter; $\mathrm{CHO}$ : community health officer; $\mathrm{CHSS}$ : community health service supervisor; $\mathrm{CHW}$ : community health worker; CHV: community health volunteer; FWA: family welfare assistant; FCHV: female community health volunteer; HA: health assistant; HEW: health extension worker; LHW: lady health worker; MS: moraghebe-salamat; MV: malaria volunteer; RV: relais volunteer; SK: shasthya korbi; SS: shasthya shebika TBA: traditional birth attendant; TBV: traditional birth volunteer; VHG: village health guide; VHV: village health volunteer; WBPHCOT: ward-based primary healthcare outreach team; WDA: Women's Development Army; VHW: village health worker 
their experiences. For example, the CHW Advocates campaign trains $\mathrm{CHWs}$ to demand their inclusion in high-level decision-making forums [33].

- Identify and support CHWs who are leaders, including CHWs who have become political leaders, so that CHWs can act as their own best advocates. ${ }^{1}$ For example the " 120 under 40 " programme recognizes and supports young leaders from the family planning movement [34].

- Identify young, unrecognized, potential leaders who already have a passion for CHWs and give them a platform to promote the CHW movement.

- Reach out to individuals and groups who are sceptical about or critical of CHWs, to engage them in discussion.

- Bridge the divide that often exists between preventive- and curative-oriented health workers.

- Emphasize the need for and uses of CHWs in high- and in middle-income countries as well as in low-income countries by showing how CHW programmes can address important health needs across settings.

\section{How can we mobilize greater investments in national CHW programmes and community platforms?}

- Work with governments to develop long-term strategies for increasing sustainable, domestic support needed for strong CHW programmes (as the Financing Alliance for Health [35] is doing).

- Develop strategies to build political will that can lead to more domestic investment for national CHW programmes [36].

- Look for opportunities to cross-subsidize CHW programmes from other revenue streams within ministries of health, from the government more broadly, and from nongovernmental organizations (NGOs).

- Encourage greater technical support from international agencies.

- Increase financial support from donors for strengthening national integrated CHW programmes. Only $2.5 \%$ of global public health donor assistance over the past decade has been devoted specifically to $\mathrm{CHW}$ programmes, and two thirds of this was for vertical programmes related to HIV/AIDS, malaria, tuberculosis, reproductive health, or family planning [37].

- Encourage multilateral and bilateral organizations to assist governments in finding sustainable global

\footnotetext{
1 There is a growing number of people, especially women, who had previously been CHWs who are now political leaders and elected officials.
}

and domestic resource streams that can be used for CHW remuneration.

\section{How can we reduce the gap between evidence and practice for increasing the population coverage of evidence-based interventions that $\mathrm{CHWs}$ can deliver (especially for reducing neonatal and child mortality)?}

- Use evidence-informed implementation strategies [38] and consider well-described barriers and facilitators to implementing CHW programmes [39] and local evidence on factors affecting implementation and how these might be addressed.

- Further develop, expand, and evaluate (using appropriate designs) programmes building on robust evidence and experience at smaller scale, such as that for women volunteers who visit their neighbours frequently and who form Care Groups, used in 30 countries around the world [40-42], and for frequent home visits by CHWs in peri-urban Mali [43], Senegal [44], and elsewhere [45, 46].

- Explore whether dual-cadre CHW programmes (using minimally trained volunteer $\mathrm{CHWs}$ working with full-time salaried CHWs or paramedical workers) can make it possible to provide the frequent home visits needed to reduce neonatal and child mortality [47].

- Explore what can be learned, scaled up, and further evaluated from exemplary programmes, including the CHW programmes analysed by Exemplars in Global Health [25].

\section{How can CHWs contribute to stronger linkages at the local level for reproductive and maternal health?}

- Develop stronger linkages for CHWs in the provision of family planning, maternal care, neonatal care, and other reproductive health services (such as mitigating gender-based violence and screening and treatment of cervical and breast cancer). For example, with women's support groups engaging with CHWs, building on the evidence-based empowerment strategies of CHW-led participatory learning and action groups used successfully in Bangladesh, India, Malawi, and Nepal for reducing maternal and neonatal mortality $[48,49]$ and $\mathrm{CHW}$-led Care Groups used by NGOs throughout the world [50].

- Develop CHW promotion of care-seeking at birthing facilities providing culturally appropriate, community-supported, high-quality care during delivery, building on experiences from rural Guatemala [51] 
and the urban low-income settlements of Bangladesh [52].

\section{How can we facilitate the expansion of $\mathrm{CHW}$ roles beyond their traditional maternal/reproductive, child health, and nutrition role without overloading them or diminishing their effectiveness?}

- The Brazilian experience informs us that a comprehensive, life-course approach is entirely feasible providing that the number of households assigned to each CHW is reasonable (currently 150-200 in Brazil) [53].

- Based on the available evidence on which interventions for NCDs (including mental health conditions) can be effectively delivered by CHWs [54-59], consider whether incorporating some or all of these functions into existing $\mathrm{CHW}$ programmes is feasible, acceptable, promotes equity, and is cost-effective.

- Support research into how to sustain at scale the role of generalist CHWs (not funded under vertical programmes) in:

1. identifying those with conditions of public health importance (e.g., HIV, tuberculosis, hypertension, diabetes, obesity, mental illness, persons with surgically treatable conditions) as well as conditions of local need (e.g., readily preventable or treatable health problems of the elderly such as presbyopia, palliative care for those with terminal conditions, pain control, basic needs for improved water and sanitation, and so forth),

2. linking them to treatment, and

3. serving as first-line providers of treatment under controlled conditions, with appropriate supervision and support.

- Support further research on the contributions of $\mathrm{CHW}$ programmes at scale in the detection and control of infectious disease outbreaks.

- Support case studies, field trials, and robust process and impact evaluations of programmes that incorporate new $\mathrm{CHW}$ roles.

- Support further research on the potential contributions of CHWs to vital events registration as well as to civil birth and death certification, and verbal autopsies.

- Engagement of local communities with the findings as well as field trials of these activities [60-63].

- Explore real-world implementation issues for $\mathrm{CHW}$ programmes with these expanded roles, determining what is necessary-in specific settings-for CHWs to perform these tasks effectively under routine programme conditions (including assessing the implications for the numbers of $\mathrm{CHWs}$ required to avoid overburden of tasks).

\section{How can vertical programmes (with their specific selective technical interventions) be better integrated within the national PHC system, including in national $\mathrm{CHW}$ programmes?}

- Document examples of how complicated and unnecessarily difficult the training, implementation, and reporting of $\mathrm{CHW}$ work can be when different vertical programmes are engaging the same $\mathrm{CHWs}$ in an uncoordinated manner.

- Document current examples of how integration has been achieved [64, 65].

- Assess the implications for the numbers of CHWs for given catchment areas.

- Afghanistan's, Ethiopia's, and Rwanda's approaches to these issues are exemplary [13].

How can we support more information sharing, research, and evaluation of national CHW programmes?

- Support information hubs and communities of practice at the global and national levels, and CHWs' access to these, including via online channels. The webstie CHW Central [66] is one example. Healthcare Information for All (HIFA), as another example, has established a working group for CHWs with the aim of promoting discussion on their health information and learning needs, and how these needs can be more effectively addressed [67].

- Provide opportunities for CHWs themselves to participate in decision-making structures as well as to express their views on their work and how they could become more effective. International forums generally have few, if any, CHWs in attendance. The efforts to engage $\mathrm{CHWs}$ at the first and second International Symposium on Community Health Workers (held in Kampala, Uganda, in 2017 and in Dhaka, Bangladesh, in 2019) are positive examples. The experiences this year with international conferences conducted entirely on a remote basis (due to COVID-19 restrictions) provide useful examples of how such convening can be done on a more inclusive basis than in the past.

- Build more communication capabilities for learning and sharing about CHW programmes and about CHWs themselves. Two current examples are (1) the 
Hesperian Health Guides programme [68], with its long experience in preparing and sharing materials for community health programming, and (2) the Last Mile Health's Community Health Academy [69].

- Support research on and evaluation of all types of $\mathrm{CHW}$ programmes, but particularly national $\mathrm{CHW}$ programmes. Further research is needed on the effectiveness of national $\mathrm{CHW}$ programmes and community health platforms that focus on implementation issues in large-scale, real-world settings. Both independent research and evaluations paid for by the governments themselves are important. The recent evaluation of the $\mathrm{CHW}$ programme in Ethiopia is an important example [70].

- National CHW programmes that are seen as models deserve intense scrutiny to understand how they operate and what appear to be key factors contributing to their performance, so this information can guide policy and programming in other countries. This involves rigorous assessments of key components. New methodologies for this approach are emerging such as the multiphase optimization strategy (MOST), which is a new methodological approach for building, optimizing, and evaluating multicomponent interventions. Conceptually rooted in engineering, MOST emphasizes efficiency and careful management of resources to move intervention science forward steadily and incrementally. MOST can be used to guide the evaluation of research evidence, develop an optimal intervention (the best set of intervention components), and enhance the translation of research findings [71].

- Make better use of routine health management information system data for regular assessments and ongoing performance management of $\mathrm{CHW}$ programmes, particularly at the local level.

\section{How can we institutionalize the principles of mapping every household, visiting every house regularly, identifying local epidemiological priorities based on local data obtained from home visits, and working collaboratively with communities to address local health priorities?}

- Develop further documentation on how programmes based on these principles have been implemented and assess their strengths and weaknesses.

- Assess the utility of the health information systems used in these programmes (family health folders linked to numbered households on village maps as has been implemented nationally in Ethiopia) and and how they can strengthen $\mathrm{CHW}$ programme effectiveness, including their linkage to vital events registration, cause of death analysis, and community engagement [72].

- Evaluate the added value of these approaches for promotion of equity.

- Document how CHWs, communities, and the peripheral health system can use these approaches to adapt national guidelines to the local context.

- Evaluate the utility of different health information systems used by CHW programmes, including how these strengthen CHW effectiveness [73].

\section{How can we develop stronger $\mathrm{CHW}$ programming in fragile states and in the context of humanitarian disasters and epidemics/pandemics?}

We know that fragile states and areas with armed conflict have higher levels of collateral mortality (especially for mothers and children) $[74,75]$ and that with adequate support, CHW programming is possible even when health facility functioning is compromised. We also know that CHWs can have important impacts in the midst of humanitarian disasters [76, 77]. Our new reality now appears to be one in which the COVID-19 pandemic will likely be here for several years (just as the $1918 \mathrm{flu}$ pandemic). There will be future pandemics, and with climate change there are likely to be more extreme weather events leading to more humanitarian disasters [78]. Therefore, there is a need to:

- Explore ways to tap rapidly into existing latent capacity among community members with previous experience in programme implementation.

- Develop and implement strategies for rapid training and scaling up of CHWs in these settings.

- Strengthen the role of CHWs for surveillance and vital events monitoring at all times.

- Undertake research on the role of CHWs during pandemics such as COVID-19, including in relation to surveillance, community mobilization, contact tracing, and so forth [79]. The CORE Group Polio Project has had extensive experience using CHWs for these types of activities as they pertain to global polio eradication [80-83]. As Ballard et al. [26] concluded, in their recent overview of the importance of CHWs for responding to the COVID-19 pandemic globally:

The investments in the supply chain, compensation, dedicated supervision, continuous training, and performance management necessary for rapid community response in a pandemic are the same as those required to achieve universal health coverage and 
prevent the next epidemic. Strengthening high-quality healthcare delivery systems will save lives, not just during COVID-19, but always. [26]

\section{How can we strengthen the role of $\mathrm{CHWs}$ in under-resourced urban settings (including informal settlements in LMICs)?}

- Gather evidence on the use of CHWs in informal urban settlements, where challenges regarding water, sanitation, hygiene, food safety, vector control, and waste management have to be dealt with in addition to other basic healthcare issues, especially for mothers and children, building on recent pioneering work $[84,85]$.

- Explore new approaches that are currently being used to strengthen health programmes in informal urban settlements using CHWs [86].

\section{What are the most appropriate roles for NGOs in CHW programming?}

- NGOs have been global leaders in pioneering the development and implementation of programmes, in community engagement, and in the research and development components of community-based PHC [87, 88]. However, NGOs and their donors have sometimes undercut government leadership, pressured governments to pursue fragmented, diseasespecific projects, and have instituted approaches that have been damaging to national health systems in the longer term. We need to explore ways of building on the strengths of NGO initiatives while also strengthening integrated, national health systems. Guiding principles for such engagement should be drawn on more widely [89].

- NGOs sometimes operate their own CHW programmes separate from government $\mathrm{CHW}$ programmes, while others are working hard to assist the government in strengthening government $\mathrm{CHW}$ programmes [89].

- NGOs have been global leaders in pioneering the development and implementation of CHW programmes as well as in community engagement $[87,88]$.

- In Afghanistan and South Sudan, among other countries, the government contracts with NGOs to run its national CHW programme. This is a model that deserves consideration for application in other settings, particularly where government services are weak and underdeveloped.
- Given the lack of authority that ministries of health in LMICs have in many urban areas (where municipal governments or national ministries of urban affairs have jurisdiction), the lack of government-run $\mathrm{CHW}$ programmes there, and the prominent role of the private sector in urban healthcare, NGOs can play an important role in $\mathrm{CHW}$ programming in urban areas as well as in implementation research pertaining to these programmes.

- NGOs have been global leaders in community health research and innovative program development [90]. They need to capitalize on this strength to continue to contribute to implementation research.

- While many policy makers consider NGOs as boutique operators that have less to offer solving global health problems at scale, there are important exceptions to this. BRAC's ${ }^{2} \mathrm{CHW}$ health programmes in Bangladesh reach over 100 million people and another 20 million people in other countries [88]. The CORE Group Polio Project coordinated the efforts of international and local national NGOs to engage communities and deploy CHWs at scale in 11 countries to address urgent needs in eradicating polio, strengthening immunization programmes more broadly, and responding to community priorities for maternal and child health [80, 83]. Moreover, many NGOs play important roles in advocating for and supporting changes in national policy-for instance, the recent provision of national-level support from multiple NGOs for community health strategy updates in Kenya.

\section{What are priority areas for $\mathrm{CHW}$ research and programme performance assessment?}

- Follow the recommendations of the 2018 WHO guidelines and focus research on (1) CHW selection, education, and certification, (2) management and supervision, and (3) integration into and support by health systems and communities [12].

- Support operations research on how to (1) ensure CHWs are provided with more reliable supplies of needed programme commodities, (2) optimize CHW work time and task allocation [91, 92], and (3) balance CHW roles and responsibilities to households, community groups, and patients coming to them for curative care. At present, Ethiopia and BRAC have established exemplary programmes that address

\footnotetext{
${ }^{2}$ BRAC (http://www.brac.net/) is the largest NGO in the world. The acronym originally referred to the Bangladesh Rural Advancement Committee and now refers to Building Resources across Communities.
} 
these issues in their programmes, and much can be learned by a closer analysis of how their programmes work [13, 25, 93].

- Support research on amplifying CHW leadership and voice, including around CHW labour rights, peer-to-peer engagement, and participation in policy decision-making.

- Support operations research on how to better provide both social and supervisory support for CHWs, notably when traditional approaches to supervision have failed or are impractical. Again, Ethiopia and BRAC are leaders.

- Investigate task overload, burnout, and career (de) motivation for CHWs. Ethiopia and Brazil are struggling with these issues and provide a good example of how these issues might be addressed.

- Develop better evidence on the full costs of strong $\mathrm{CHW}$ programmes and the comparative value of investing in them along with improved facility-based services as against the alternative (i.e., improving facility-based services without improved CHW services).

- Develop better documentation of how national CHW programmes function. Health for the People [13] is one small step in that direction.

- Build the evidence base on the role of CHWs in urban settings. Research in the area is quite limited at present.

- Continue to explore how we can use digital technologies to support CHWs in their work [72, 94].

- Build leadership and momentum for longitudinal evaluation and learning for adaptive community health platforms in partnership with communities, CHWs, and the local health system) [95].

- Further document and promote efforts to promote local government engagement for strengthening CHW programming $[96,97]$.

- Further document and promote community engagement strategies for the selection and priority setting of community activities, support to communitybased structures, and involvement of community representatives in decision-making, problem-solving, planning, and budgeting processes as they relate to CHW activities [98].

\begin{tabular}{l}
\hline Discussion \\
Key message box 4 \\
The global experience and the scientific evidence are \\
unequivocal: CHWs are among the most cost-effective \\
and the most rapidly implementable approaches to \\
improve the health of underserved populations. Our \\
task now is to provide national CHW programmes \\
with the resources and technical support to enable \\
them to reach their full potential.
\end{tabular}

As national $\mathrm{CHW}$ programmes grow increasingly important for health systems and community health, there will be a need for new thinking and, importantly, for stronger political and financial support. We also need to consider how to increase the population coverage of evidence-based interventions that CHWs can provide, how to adapt programme elements that have been used by other effective programmes, and how to redirect attention to epidemiological priorities. Mechanisms for strengthening the monitoring and evaluation of programmes, including expanded implementation research, are also critical.

\section{Change our mental models, giving greater recognition to CHWs and communities as central components of health systems}

We are long past due for a shift in our understanding of $\mathrm{CHW}$ programmes, from viewing them as a temporary and underfunded afterthought, to seeing them as an integral component of optimally functioning health systems anywhere in the world, including high-income countries and LMICs.

At the same time, we need also to recognize communities as an integral part of health systems-a key component of the health system that was initially ignored when the systems building blocks were first conceptualized by WHO in 2007 [99]. The lack of inclusion of communities and community-based services in frameworks for health systems strengthening is striking [100]. An expansion of the six WHO building blocks has been proposed that highlights community-based service delivery as well as community mobilizing and organization, with attention to nontraditional health system components such as social capital, inter-sectoral partnerships, local governance, equitable financing, community information and data systems, and household production of health [101]. After all, as the most important stakeholders in the health system, individuals, households, and communities must be enabled to demand healthcare that is responsive to their needs and concerns, and that works collaboratively with them to improve their own health and well-being.

In recognizing that communities are integral to health systems, we do not mean to imply that facility-based services are not vital and should not also be strengthened. $\mathrm{CHW}$ programmes rely on support from their nearest facilities, and without adequately functioning facilities, patients referred by CHWs will not be able to receive proper care, thereby undermining $\mathrm{CHW}$ programme functioning.

CHWs are firmly ingrained in the mental models of many of us as being relevant only for poorer countries. We need to change this [102]. The number of CHWs in the United States is growing rapidly in response to 
persistent gaps in the health system [103, 104], and they are serving an important role in the COVID-19 pandemic response [29]. The United States Government's Fiscal Year 2021 Reconciliation Act (American Rescue Plan) provides $\$ 7.6$ billion in funding to public health departments to hire 100,000 full-time employees into the public health workforce. This will include CHWs, among others, who will hopefully become a permanent cadre in the health sector $[105,106]$. As noted above, proposals have also been made to establish a permanent $\mathrm{CHW}$ cadre in the United Kingdom [28].

\section{Provide more support for implementation research on $\mathrm{CHW}$ programming}

In its guidelines for health policy and system support to optimize CHW programmes, WHO noted that although there is a rich body of literature on CHW programming, there is a striking lack of rigorous research on $\mathrm{CHW}$ programme effectiveness that can provide practical guidance on programme implementation [12]. Large-scale randomized controlled trials cannot provide the needed evidence. Evidence needs to come from comprehensive, critical programme case studies and from investigations not only on what works but also on what conditions are required for such programmes to perform well (including health system requirements) [13]. Given the great deal of evidence on the effectiveness of CHW programmes operating under ideal, small-scale and short-term conditions $[20,22]$, more research is needed on programmes operating at scale uunder routine conditions for the longer term. Building and making use of local capacity for this type of research is needed.

As mentioned above, the WHO guidelines draw attention to the need for research on selection and training, management and supervision, and integration into and support by health systems and communities [12]. Other work has identified further priority research questions including on effective policy, financing, governance, supervision and monitoring systems, the role of digital technologies, $\mathrm{CHW}$ preferences, drivers of $\mathrm{CHW}$ motivation and retention over time, and $\mathrm{CHW}$ rights and well-being [107].

A key need identified within this research agenda is to document and evaluate strategies that help to ensure that $\mathrm{CHW}$ programs work optimally, since there is already considerable evidence for effectiveness of the interventions they are expected to deliver. As Frankel observed almost three decades ago (in 1992),

There is no longer any place for discussion of whether CHWs can be key actors in achieving adequate health care. The question is how to achieve their potential. [108], p. 1

Thus, we need to determine what conditions need to be met at scale so that $\mathrm{CHW}$ programmes and community engagement can reach their full potential. For instance, Hazel et al. [109] have documented the disappointing results of evaluations of CHW programmes that employed integrated community case management (iCCM) for childhood illness in Burkina Faso, Ethiopia, and Malawi regarding the quality of care provided by CHWs, the low utilization of their services, the low population coverage of $\mathrm{CHW}$ services, and the absence of a demonstrated impact on mortality. This work concludes that instead of discarding iCCM as a component of $\mathrm{CHW}$ programming, we need instead to think of CHW programmes as requiring, just as human infants do, "steadfast attention, investment, and development guidance to mature and achieve their mortality reduction potential" [109]. Ongoing programme evaluations and implementation research are needed to continually refine, develop, and modify CHW programmes. And, importantly, these authors note that "[l] ocal capacity to collect and analyze relevant data is a prerequisite for generating essential knowledge and putting this knowledge to use" [109].

We also need to shorten the lag time between generation of evidence and its application. Too often we find ourselves faced with a dilemma-there is a lack of evidence to guide implementation, and there is a lack of implementation because of a lack of evidence. But there is also plenty of evidence that is not being acted upon.

\section{Build stronger political and financial support}

We need to build mutual support and collaboration among health workers, the lack of which has hindered effectiveness of $\mathrm{CHW}$ programmes. In many countries, professional associations of nurses and physicians have opposed the introduction of CHW programmes as well as efforts to delegate authority to CHWs to manage dispensing medication (e.g., childhood pneumonia and malaria). This has occurred even where we have robust evidence demonstrating that these tasks can be performed safely and effectively by well-trained and supervised CHWs [110]. We need to ensure that training encourages respect and complementarity among nurses, doctors, CHWs, and other health cadres rather than positioning one another as threats or opponents.

Further, we need to convince government leaders, political leaders, medical opinion leaders, civic society, and local grassroots leaders of the importance of $\mathrm{CHW}$ programmes, the value of strengthening them, and the benefits that can be achieved by expanding government financial support for them. 


\section{Expand the population coverage of evidence-based interventions}

Based on modelling, it has been estimated that if we could raise the population coverage of current evidencebased maternal-child interventions that can be implemented at the community level by CHWs to $90 \%$ in the 74 countries with $97 \%$ of the child and maternal mortality in the world, an additional 2.6 million maternal and child deaths could be averted each year [111]. This does not include the additional benefits that would accrue by expanding community-based family planning services [111]. The interventions with the greatest potential still have low levels of population coverage.

\section{Adapt programme elements that have been used by other effective programmes}

A review of community-based $\mathrm{PHC}$ in improving maternal, neonatal, and child health [20] identified four strategies for which there is good evidence of effectiveness:

- home visitation,

- participatory women's groups,

- community case management of childhood illness, and

- provision of outreach services by mobile health teams [112].

The evidence base for these strategies needs to be expanded further, and these strategies need to be more widely adopted and scaled up. Community case management of childhood illness, using proactive frequent home visitation, has shown promising results as a strategy for reducing under-five mortality in Mali and for improving access to care in Senegal, in which CHWs are well supplied with the medicines they need [43, 44]. Another promising approach is tiered $\mathrm{CHW}$ programme delivery: dual-cadre $\mathrm{CHW}$ programmes and even triple-cadre programmes are now emerging. Both approaches merit further replication and ongoing assessments.

\section{Give continuing emphasis to the potential for $\mathrm{CHWs}$ to address the most frequent, serious, readily preventable or treatable conditions (i.e., epidemiological priorities)}

This involves supporting CHW activities that directly address the leading causes of neonatal and perinatal mortality, childhood undernutrition, and under-five mortality (from pneumonia, diarrhoea, and malaria) [113]. It also involves identifying and linking pregnant women with appropriate care, identifying persons with unrecognized hypertension and diabetes, and providing them with firstline treatment or linking them to sources of facility-based
PHC. Finally, it involves supporting those with long-term physical and mental disabilities.

\section{Strengthen monitoring and surveillance}

CHWs have the potential to identify local epidemiological priorities based on routine home visitation, including detection of disease outbreaks and registration of vital events (which can also be entered into the civil registration system), with support from mobile devices, as may be appropriate to the context [114-116]. These activities are particularly applicable in fragile and conflictaffected states where facility-based services are weak or nonfunctional.

\section{Conclusion}

It is time to acknowledge the important contributions that CHW programmes can make. Programmes for $\mathrm{CHWs}$ and community health, integrated within national health systems, should share pride of place with other global health priorities and garner comparable levels of financial and policy support, technical leadership, and prominence in the organizational architecture of global health.

At the same time, it is necessary to recognize that CHW programmes and community health initiatives more broadly remain relatively underdeveloped areas of endeavour in global public health in terms of (1) the number of professionals working to advance the field, (2) investments in expanding the evidence base, and (3) investigations into the factors affecting implementation effectiveness at scale.

We now know enough to conclude that-when designed appropriately to context and adequately supported-CHW programmes and community health initiatives can accelerate progress in achieving population heath goals and in reducing health disparities. Support for new thinking, innovative programming, and research, including implementation research, is urgently needed, recognizing that a return on this investment of effort will take time.

Taking the longer-term view, now is the time to invest in the following:

1. Providing opportunities for political leaders, programme managers, and other stakeholders to visit exemplary national CHW programmes to learn, firsthand, how they have embedded CHW programmes in the community and integrated them within the national health system.

2. Exposing such decision-makers to local and international conferences and seminars where learning from various countries on these programmes is shared. 
3. Providing decision-makers as well as community members and leaders with high-quality information on why national $\mathrm{CHW}$ programmes are important, on the financial, social, and technical conditions for their success, and on the need to strengthen them.

4. Developing better metrics that can be widely shared with communities on levels of government funding currently going to hospitals, PHC facilities, and to community outreach/CHW programming.

5. Assessing the past several decades of experience with the promotion of family planning, immunizations, and other vertical programmes, and incorporating lessons learned from strengthening these programmes into a strategy for strengthening PHC, including national $\mathrm{CHW}$ programmes.

In 2019, the United Nations called on all governments to invest an additional 1\% of their GDP in expanding and strengthening their PHC systems in order to achieve UHC [117]. UHC will be required to achieve the SDGs. In order to make this additional investment optimally productive, a major share of this investment will need to be directed towards community initiatives, including $\mathrm{CHW}$ programmes. The current level of investment in CHW programmes and community health is poorly documented, but it will need to grow substantially [118].

A strong commitment by governments to community health initiatives, including CHW programming, will give a major boot at this critical moment will encourage donors and technical support organizations to follow suit. As Sherry, Ghaffar, and Bishai astutely observe, "without initiatives to help community health platforms flourish around the world, the health gains promised by [specific evidence-based technical] interventions will cost more and deliver less.... With the availability of local data, local forums for sharing data, and local multi-sectoral stakeholder engagement, [such technical] solutions will work better and deliver more" [119].

One of us (Mushtaque Chowdhury) recently noted:

In the long-term interests of the health care sector of the country, we believe CHWs should be systematically trained and integrated within the health system. We would like to see that they are recognized, at long last, as valued health professionals, something they are, and are paid as such too. This, for Bangladesh, is well within the realm of what is possible. Such choices should not be viewed as secondbest solutions for the poor but the best bet for health, and for addressing this pandemic and others which are likely to come. We urge that we build on these tested local strengths as a priority rather than aiming to replicate high-cost medical interventions with limited, and in some instances, unproven, prospects of efficacy. [120]

Calls are being made for the establishment of a national CHW cadre in the United Kingdom [28] and for a community health corps in the United States $[29,30]$ to carry out similar functions - to assist in controlling the COVID-19 pandemic but also to strengthen the health system moving forward and to be able to be better prepared for future pandemics.

The potential for CHWs and for community engagement, more broadly, to serve as an integral component of PHC exceeds what can be achieved by facility-based care alone. This is true not only for ending preventable child and maternal deaths, but also for better controlling NCDs. Furthermore, in many countries, CHWs are the frontline of defence against the COVID-19 pandemic. Thus, there are now calls throughout the world for CHWs to be appropriately supported (and protected) to enable them to play a key frontline role against the pandemic and then, moving forward, a key part of the foundation of health systems.

By enabling national $\mathrm{CHW}$ programmes to reach their full potential, they in turn can lead the way toward accelerating progress in reducing inequities in health and achieving health for all. "If it happens in the community, it happens in the nation. It if does not happen in the community, it does not happen at all" (Miriam K. Were, personal communication).

\section{Abbreviations \\ AIDS: Acquired immunodeficiency syndrome; CHW: Community health worker; COVID: Coronavirus disease; HIV: Human immunodeficiency virus; iCCM: Integrated community case management (of childhood illness); MOST: Multiphase optimization strategy; NCDs: Noncommunicable diseases; NGO: Nongovernmental organization; PHC: Primary healthcare; SDGs: Sustainable Development Goals; UHC: Universal Health Coverage.}

\section{Acknowledgements}

We are grateful for the financial support from the Bill \& Melinda Gates Foundation and the United States Agency for International Development that made this work possible. We also express our appreciation to members of the writing team that produced the book that served as a basis for this article (Developing and Strengthening Community Health Worker Programs at Scale: A Reference Guide and Case Studies for Program Managers and Policy Makers, available at: https://www.mchip.net/sites/default/files/mchipfiles/CHW_Refer enceGuide_sm.pdf).

\section{About this supplement}

This article has been published as part of Health Research Policy and Systems Volume 19, Supplement 3 2021: Community Health Workers at the Dawn of a New Era. The full contents of the supplement are available at https://healthpolicysystems.biomedcentral.com/articles/supplements/volume-19-suppl ement-3.

\section{Authors' contributions}

HP conceived of this article and wrote the first draft. MW, KL, LC, SL, DM, $\mathrm{MK}, \mathrm{KS}, \mathrm{MB}$, and $\mathrm{SH}$ contributed to subsequent drafts. All authors read and approved the final manuscript. 


\section{Funding}

Dr Perry's contribution as well as publication expenses were supported in part by the Bill \& Melinda Gates Foundation (Investment ID OPP 1197181) and by the Maternal and Child Health Integrated Program (MCHIP) of Jhpiego, funded by the United States Agency for International Development. The funders had no role in the conduct of our work.

\section{Availability of data and materials}

Any articles and other materials cited by the authors are available from the corresponding author.

\section{Declarations}

Ethics approval and consent to participate

Not applicable.

\section{Consent for publication}

Not applicable.

\section{Competing interests}

The authors declare that they have no competing interests.

\begin{abstract}
Author details
${ }_{1}^{1}$ Department of International Health, Johns Hopkins Bloomberg School of Public Health, Baltimore, MD, USA. ${ }^{2}$ BRAC University, Dhaka, Bangladesh. ${ }^{3}$ UZIMA Foundation, Nairobi, Kenya. ${ }^{4}$ Independent Consultant, Washington, DC, USA. ${ }^{5}$ Crigler Consulting, LLC, Hillsborough, NC, USA. ${ }^{6}$ Norwegian Institute of Public Health, Oslo, Norway and Health Systems Research Unit, South African Medical Research Council, Cape Town, South Africa. ${ }^{7}$ Department of Disease Control and Environmental Health, School of Public Health, College of Health Sciences, Makerere University, Kampala, Uganda. ${ }^{8}$ Department of Global Health, KIT Royal Tropical Institute, Amsterdam, The Netherlands. ${ }^{9}$ Independent Consultant, Toronto, Canada. ${ }^{10}$ Community Health Impact Coalition, New York, NY, USA. ${ }^{11}$ Department of Health System Design and Global Health, Icahn School of Medicine at Mount Sinai, New York City, NY, USA.

${ }^{12} \mathrm{School}$ of Public Health, University of Alberta, Edmonton, AB, Canada.
\end{abstract}

\section{Received: 16 June 2021 Accepted: 17 June 2021}

Published: 12 October 2021

\section{References}

1. Hodgins S, Lewin S, Glenton C, LeBan K, Crigler I, Musoke D, Kok M, Perry H: Community health workers at the dawn of a new era: 1. Introduction and tensions confronting programs. BMC Health Res Policy Syst. 2021. https://doi.org/10.1186/s12961-021-00752-8.

2. Afzal M, Pariyo G, Perry H: Community health workers at the dawn of a new era: 2. Planning, coordination, and partnerships. BMC Health Res Policy Syst. 2021. https://doi.org/10.1186/s12961-021-00753-7.

3. Lewin S, Lehmann U, Perry H: Community health workers at the dawn of a new era: 3. Program governance. BMC Health Res Policy Syst. 2021. https://doi.org/10.1186/s12961-021-00749-3.

4. Masis L, Gichaga A, Lu C, Perry H: Community health workers at the dawn of a new era: 4. Program financing. BMC Health Res Policy Syst. 2021. https://doi.org/10.1186/s12961-021-00751-9.

5. Glenton C, Javadi D, Perry H: Community health workers at the dawn of a new era: 5. Roles and tasks. BMC Health Res Policy Syst. 2021. https:// doi.org/10.1186/s12961-021-00748-4.

6. Schleiff M, Aitken I, Perry H: Community health workers at the dawn of a new era: 6. Training. BMC Health Res Policy Syst. 2021. https://doi.org/ 10.1186/s12961-021-00757-3.

7. Carpenter C, Musoke D, Crigler L, Perry H: Community health workers at the dawn of a new era: 7. Supervision. BMC Health Res Policy Syst. 2021. https://doi.org/10.1186/s12961-021-00754-6.

8. Colvin C, Hodgins S, Perry H. Community health workers at the dawn of a new era: 8 . Incentives and remuneration. BMC Health Res Policy Syst. 2021. https://doi.org/10.1186/s12961-021-00750-w.

9. LeBan K, Kok M, Perry H. Community health workers at the dawn of a new era: 9. CHWs'relationships with the health system and the community. Health Res Policy Syst. 2021. https://doi.org/10.1186/ s12961-021-00756-4.

10. Kok M, Crigler L, Kok M, Ballard M, Musoke D, Hodgins S, Perry H. Community health workers at the dawn of a new era: 10. Program performance and its assessment. BMC Health Res Policy Syst. 2021. https:// doi.org/10.1186/s12961-021-00758-2.

11. Developing and Strengthening Community Health Worker Programs at Scale: A Reference Guide and Case Studies for Program Managers and Policy Makers. http://www.mchip.net/sites/default/files/mchipfiles/ CHW_ReferenceGuide_sm.pdf. Accessed 11 Apr 2021

12. WHO guideline on health policy and system support to optimize community health worker programmes. https://apps.who.int/iris/bitstream/ handle/10665/275474/9789241550369-eng.pdf?ua=1. Accessed 11 Apr 2021

13. Health for the People: National Community Health Programs from Afghanistan to Zimbabwe. [https://pdf.usaid.gov/pdf_docs/PA00WKKN. pdf. Accessed 11 Apr 2021

14. Declaration of Astana. https://www.who.int/docs/default-source/prima ry-health/declaration/gcphc-declaration.pdf. Accessed 11 Apr 2021

15. Resolution adopted by the General Assembly on 10 October 2019: Political declaration of the high-level meeting on universal health coverage. https://undocs.org/en/A/RES/74/2.

16. Assefa Y, Tesfaye D, Damme WV, Hill PS. Effectiveness and sustainability of a diagonal investment approach to strengthen the primary healthcare system in Ethiopia. Lancet. 2018;392:1473-81.

17. Assefa Y, Gelaw YA, Hill PS, Taye BW, Van Damme W. Community health extension program of Ethiopia, 2003-2018: successes and challenges toward universal coverage for primary healthcare services. Global Health. 2019;15:24.

18. Address by Dr. Tedros Adhanom Ghebreyesus, Director-General. http:// apps.who.int/gb/ebwha/pdf_files/WHA72/A72_3-en.pdf. Accessed 11 Apr 2021

19. Community health workers delivering primary health care: opportunities and challenges. http://apps.who.int/gb/ebwha/pdf_files/WHA72/ A72_R3-en.pdf. Accessed 11 April 2021

20. Perry HB, editor. Engaging communities for improving mothers' and children's health: reviewing the evidence of effectiveness in resourceconstrained settings. Edinburgh: Edinburgh University Global Health Society; 2017.

21. Black RE, Taylor CE, Arole S, Bang A, Bhutta ZA, Chowdhury AMR, Kirkwood BR, Kureshy N, Lanata CF, Phillips JF, et al. Comprehensive review of the evidence regarding the effectiveness of community-based primary health care in improving maternal, neonatal and child health: 8. Summary and recommendations of the Expert Panel. J Glob Health. 2017;7:010908.

22. Lewin S, Munabi-Babigumira S, Glenton C, Daniels K, Bosch-Capblanch X, van Wyk BE, Odgaard-Jensen J, Johansen M, Aja GN, Zwarenstein M, Scheel IB. Lay health workers in primary and community health care for maternal and child health and the management of infectious diseases. Cochrane Database Syst Rev. 2010;3:4015.

23. Glenton C, Scheel IB, Lewin S, Swingler GH. Can lay health workers increase the uptake of childhood immunisation? Systematic review and typology. Trop Med Int Health. 2011;16:1044-53.

24. Black RE, Levin C, Walker N, Chou D, Liu L, Temmerman M, Group DRA. Reproductive, maternal, newborn, and child health: key messages from Disease Control Priorities. Lancet. 2016; 388:2811-24.

25. Community Health Workers. https://www.exemplars.health/topics/ community-health-workers. Accessed 11 Apr 2021

26. Ballard M, Bancroft E, Nesbit J, Johnson A, Holeman I, Foth J, Rogers D, Yang J, Nardella J, Olsen $\mathrm{H}$, et al. Prioritising the role of community health workers in the COVID-19 response. BMJ Glob Health. 2020;5:74.

27. Community health workers are crucial to pandemic response. How to support them. https://theconversation.com/community-health-worke rs-are-crucial-to-pandemic-response-how-to-support-them-134908. Accessed 11 Apr 2021

28. Haines A, de Barros EF, Berlin A, Heymann DL, Harris MJ. National UK programme of community health workers for COVID-19 response. Lancet. 2020;395:1173-5.

29. Waters R. Community Workers Lend Human Connection To COVID-19 Response. Health Aff (Millwood). 2020;39:1112-7. 
30. Goldfield NI, Crittenden R, Fox D, McDonough J, Nichols L, Lee Rosenthal E. COVID-19 crisis creates opportunities for communitycentered population health: community health workers at the center. J Ambul Care Manage. 2020;43:184-90.

31. Rodin J, de Ferranti D. Universal health coverage: the third global health transition? Lancet. 2012;380:861-2.

32. Jamison DT, Summers LH, Alleyne G, Arrow KJ, Berkley S, Binagwaho A, Bustreo F, Evans D, Feachem RG, Frenk J, et al. Global health 2035: a world converging within a generation. Lancet. 2013;382:1898-955.

33. CHW Advocates. https://www.chwadvocates.org/. Accessed 11 Apr 2021

34. 120 Under 40: The New Generation of Family Planning Leaders. https:// www.120under40.org/. Accessed 11 Apr 2021

35. The Financing Alliance for Health. http://www.financingalliance.org/. Accessed 11 Apr 2021

36. Healey J, Wiah SO, Horace JM, Majekodunmi DB, Duokie DS. Liberia's community health assistant program: scale, quality, and resilience. Glob Health Sci Pract. 2021;9:S18-24.

37. Lu C, Palazuelos D, Luan Y, Sachs SE, Mitnick CD, Rhatigan J, Perry HB. Development assistance for community health workers in 114 lowand middle-income countries, 2007-2017. Bull World Health Organ. 2020;98:30-9.

38. Pantoja T, Opiyo N, Lewin S, Paulsen E, Ciapponi A, Wiysonge CS, Herrera CA, Rada G, Penaloza B, Dudley L, et al. Implementation strategies for health systems in low-income countries: an overview of systematic reviews. Cochrane Database Syst Rev. 2017:9:11086.

39. Glenton C, Colvin C, Carlsen B, Swartz A, Lewin S, Noyes J, Rashidian A. Barriers and facilitators to the implementation of lay health worker programmes to improve access to maternal and child health: qualitative evidence synthesis. Cochrane Database Syst Rev. 2013;8:25.

40. Perry H, Morrow M, Borger S, Weiss J, DeCoster M, Davis T, Ernst P. Care Groups I: An Innovative Community-Based Strategy for Improving Maternal, Neonatal, and Child Health in Resource-Constrained Settings. Glob Health Sci Pract. 2015;3:358-69.

41. Perry H, Morrow M, Davis T, Borger S, Weiss J, DeCoster M, Ricca J, Ernst P. Care Groups II: a summary of the maternal, neonatal and child health outcomes achieved in high-mortality, resource-constrained settings. Global Health Sci Pract. 2015:3:370-81.

42. Weiss J, Makonnen R, Sula D. Shifting management of a community volunteer system for improved child health outcomes: results from an operations research study in Burundi. BMC Health Serv Res. 2015;15(Suppl 1):S2

43. Johnson AD, Thiero O, Whidden C, Poudiougou B, Diakite D, Traore F, Samake S, Kone D, Cisse I, Kayentao K. Proactive community case management and child survival in periurban Mali. BMJ Glob Health. 2018;3:e000634

44. Gaye S, Kibler J, Ndiaye JL, Diouf MB, Linn A, Gueye AB, Fall FB, Ndiop M, Diallo I, Cisse $M$, et al. Proactive community case management in Senegal 2014-2016: a case study in maximizing the impact of community case management of malaria. Malar J. 2020;19:166.

45. Whidden C, Thwing J, Gutman J, Wohl E, Leyrat C, Kayentao K, Johnson AD, Greenwood B, Chandramohan D. Proactive case detection of common childhood illnesses by community health workers: a systematic review. BMJ Glob Health. 2019;4:e001799.

46. Sadruddin S, Pagnoni F, Baugh G. Lessons from the integrated community case management (iCCM) Rapid Access Expansion Program. J Glob Health. 2019;9:20101.

47. McPherson R, Hodgins S. Postnatal home visitation: lessons from country programs operating at scale. J Glob Health. 2018;8:10422.

48. Prost A, Colbourn T, Seward N, Azad K, Coomarasamy A, Copas A, Houweling TA, Fottrell E, Kuddus A, Lewycka $S$, et al. Women's groups practising participatory learning and action to improve maternal and newborn health in low-resource settings: a systematic review and meta-analysis. Lancet. 2013;381:1736-46.

49. WHO recommendation on community mobilization through facilitated participatory and action cycles with women's groups for maternal and newborn health. https://apps.who.int/iris/bitstream/handle/10665/ 127939/9789241507271_eng.pdf?sequence=1\&ua=1. Accessed 11 Apr 2021

50. Perry H, Morrow M, Davis T, Borger S, Weiss J, DeCoster M, Ricca J, Ernst P. Care Groups II: a summary of the child survival outcomes achieved using volunteer community health workers in resource-constrained settings. Glob Health Sci Pract. 2015;3:370-81.

51. Stollak I, Valdez M, Rivas K, Perry H. Casas maternas in the rural highlands of guatemala: a mixed-methods case study of the introduction and utilization of birthing facilities by an indigenous population. Glob Health Sci Pract. 2016;4:114-31.

52. Community-Based Approaches to Health: How Engaging Local Community Members Can Transform the Health of Hard-to-Reach Populations. https://www.impact.upenn.edu/high-impact-giving-guide-2018/ health/brac-manoshi-project/. Accessed 11 Apr 2021

53. Harris M, Haines A. Brazil's family health programme. BMJ. 2010;341:c4945.

54. Costa EF, Guerra PH, Santos TI, Florindo AA. Systematic review of physical activity promotion by community health workers. Prev Med. 2015;81:114-21.

55. Kim K, Choi JS, Choi E, Nieman CL, Joo JH, Lin FR, Gitlin LN, Han HR. Effects of community-based health worker interventions to improve chronic disease management and care among vulnerable populations: a systematic review. Am J Public Health. 2016;106:e3-28.

56. Raphael JL, Rueda A, Lion KC, Giordano TP. The role of lay health workers in pediatric chronic disease: a systematic review. Acad Pediatr. 2013;13:408-20.

57. Small N, Blickem C, Blakeman T, Panagioti M, Chew-Graham CA, Bower P. Telephone based self-management support by "lay health workers" and "peer support workers" to prevent and manage vascular diseases: a systematic review and meta-analysis. BMC Health Serv Res. 2013;13:533.

58. van Ginneken N, Tharyan P, Lewin S, Rao GN, Meera SM, Pian J, Chandrashekar S, Patel V. Non-specialist health worker interventions for the care of mental, neurological and substance-abuse disorders in low- and middle-income countries. Cochrane Database Syst Rev. 2013;58:9149.

59. Palazuelos $D$, Jabateh $L M$, Choi $M$, Jimenez $A$, Hing $M$, Iberico MM, Nhlema B, Wroe E. Early lessons from launching an innovative community health household model across 3 country contexts. Glob Health Sci Pract. 2021;9:S168-78.

60. Vasudevan L, Henschke N, Glenton C, Lewin S, Maayan N, Eyers J, Fonhus M, Tamrat T, Mehl G. Birth and death notification via mobile devices. Cochrane Database Syst Rev. 2018. https://doi.org/10.1002/14651858. CD012909.

61. AbouZahr C, de Savigny D, Mikkelsen L, Setel PW, Lozano R, Nichols E, Notzon F, Lopez AD. Civil registration and vital statistics: progress in the data revolution for counting and accountability. Lancet. 2015;12:945.

62. Suthar AB, Khalifa A, Yin S, Wenz K, Ma Fat D, Mills SL, Nichols E, AbouZahr C, Mrkic S. Evaluation of approaches to strengthen civil registration and vital statistics systems: a systematic review and synthesis of policies in 25 countries. PLoS Med. 2019;16:e1002929.

63. Nichols EK, Ragunanthan NW, Ragunanthan B, Gebrehiwet H, Kamara K. A systematic review of vital events tracking by community health agents. Glob Health Action. 2019;12:1597452.

64. Damtew Z, Lemma S, Zulliger R, Moges A, Teklu A, Perry H. Ethiopia's Health Extension Program. In: Perry H, editor. Health for the People: National Community Health Programs from Afghanistan to Zimbabwe. Washingon: USAID/Maternal and Child Survival Program; 2020. p. 75-86.

65. Joardar T, Javadi D, Gergen J, Perry H. The BRAC Shasthya Shebika and Shasthya Kormi Community Health Workers in Bangladesh. In: Perry H, editor. Health for the People: National Community Health Programs from Afghanistan to Zimbabwe. Washington: USAID/Jhpiego/Maternal and Child Survival Program; 2020.

66. CHW Central: A Global Resource for and about Community Health Workers. https://chwcentral.org/. Accessed 11 Apr 2021

67. Healthcare Information for All. https://www.hifa.org/. Accessed 11 Apr 2021

68. Hesperian Health Guides. https://hesperian.org/. Accessed 11 Apr 2021

69. Community Health Academy. https://lastmilehealth.org/what-we-do/ community-health-academy/. Accessed 11 Apr 2021.

70. Teklu A, Alemayehu Y. National Assessment of the Ethiopian Health Extension Program. Addis Ababa, Ethiopia: MERQ Consultancy PLC; 2019.

71. Collins LM, Baker TB, Mermelstein RJ, Piper ME, Jorenby DE, Smith SS, Christiansen BA, Schlam TR, Cook JW, Fiore MC. The multiphase 
optimization strategy for engineering effective tobacco use interventions. Ann Behav Med. 2011;41:208-26.

72. WHO guideline: recommendations on digital interventions for health system strengthening. Geneva, Switzerland: World Health Organization; 2019. https://www.who.int/reproductivehealth/publications/digitalinterventions-health-system-strengthening/en/. Accessed 11 Apr 2021

73. Leon N, Balakrishna Y, Hohlfeld A, Odendaal WA, Schmidt BM, Zweigenthal V, Anstey Watkins J, Daniels K. Routine Health Information System (RHIS) improvements for strengthened health system management. Cochrane Database Syst Rev. 2020;8:12012.

74. Wagner Z, Heft-Neal S, Bhutta ZA, Black RE, Burke M, Bendavid E. Armed conflict and child mortality in Africa: a geospatial analysis. Lancet. 2018;392:857-65.

75. Wagner Z, Heft-Neal S, Wise PH, Black RE, Burke M, Boerma T, Bhutta ZA, Bendavid $E$. Women and children living in areas of armed conflict in Africa: a geospatial analysis of mortality and orphanhood. Lancet Glob Health. 2019;7:e1622-31.

76. Horton A, Silwal R, Simkhada P. A survey study on the role of Female Community Health Volunteers (FCHVs) in Nepal, during and following the 2015 earthquakes. Int J Disast Risk Red. 2020;48:101583.

77. Miller NP, Ardestani FB, Dini HS, Shafique F, Zunong N. Community health workers in humanitarian settings: Scoping review. J Glob Health. 2020;10:20602.

78. Jones KE, Patel NG, Levy MA, Storeygard A, Balk D, Gittleman JL, Daszak P. Global trends in emerging infectious diseases. Nature. 2008:451:990-3.

79. Prevent, detect, respond: how community health workers can help in the fight against covid-19. https://blogs.bmj.com/bmj/2020/03/27/ prevent-detect-respond-how-community-health-workers-can-helpfight-covid-19/. Accessed 11 Apr 2021

80. Losey L, Ogden E, Bisrat F, Solomon R, Newberry D, Coates E, Ward D. HIlmi L, Burrowes V, LeBan K, Perry HB: The CORE Group Polio Project: An Overview of Its History and Its Contributions to the Global Polio Eradication Initiative. Am J Trop Med Hyg. 2019;101:4-14.

81. Kisanga A, Abiuda B, Walyaula P, Losey L, Samson O. Evaluation of the functionality and effectiveness of the core group polio project's community-based acute flaccid paralysis surveillance system in South Sudan. Am J Trop Med Hyg. 2019;101:91-9.

82. Arale A, Lutukai M, Mohamed S, Bologna L, Stamidis KV. Preventing importation of poliovirus in the horn of Africa: the success of the cross-border health initiative in Kenya and Somalia. Am J Trop Med Hyg. 2019:101:100-6.

83. Perry H, Solomon V, Bisrat F, Hilmi L, Stamidis K, Steinglass R, Weiss W, Losey L, Ogden E. Lessons learned from community engagement, community-based programming for polio eradication, and the CORE Group Polio Project: their relevance for ending preventable child and maternal deaths. Am J Trop Med Hyg. 2019;101:107-12.

84. Ludwick T, Morgan A, Kane S, Kelaher M, McPake B. The distinctive roles of urban community health workers in low- and middle-income countries: a scoping review of the literature. Health Policy Plan. 2020;4:245.

85. Wahl B, Lehtimaki S, Germann S, Schwalbe N. Expanding the use of community health workers in urban settings: a potential strategy for progress towards universal health coverage. Health Policy Plan. 2020;35:91-101

86. Marcil L, Afsana K, Perry HB. First Steps in Initiating an Effective Maternal, Neonatal, and Child Health Program in Urban Slums: the BRAC Manoshi Project's Experience with Community Engagement, Social Mapping, and Census Taking in Bangladesh. J Urban Health. 2016;93:6-18.

87. Perry HB, Rohde J. The Jamkhed comprehensive rural health project and the Alma-Ata vision of primary health care. Am J Public Health. 2019;22:e1-6.

88. Chowdhury A, Perry H. NGO Contributions to Community Health and Primary Health Care: Case Studies on BRAC (Bangladesh) and the Comprehensive Rural Health Project, Jamkhed (India). In Oxford Research Encyclopedia, Global Public Health. New York: Oxford University Press USA; 2020.

89. Walker PR, Downey S, Crigler L, LeBan K. CHW “Principles of Practice": Guiding principles for non-governmental organizations and their partners for coordinated national scale-up of community health worker programs. Washington: CORE Group/World Vision International; 2013. p. 21.
90. Ballard M, Schwarz R. Employing practitioner expertise in optimizing community healthcare systems. Healthcare (Amst). 2019;7:100334.

91. Morrow M, Sarriot E, Nelson A, Sayinzoga F. Applying the community helath worker coverage and capacity tool for time-use modeling for program planning in Rwanda and Zanzibar. Global Health Sci Pract. 2021;9:565-78.

92. Pascal Saint-Firmin P, Diakite B, Ward K, Benard M, Stratton S, Ortiz C, Dutta A, Traore S. Community health worker program sustainability in Africa: evidence from costing, financing, and geospatial analyses in Mali. Glob Health Sci Pract. 2021;9:S79-97.

93. Hodgins S. Learning from community health worker programs, big and small. Glob Health Sci Pract. 2020;8:147-9.

94. Kirk K, McClair TL, Dakouo SP, Abuya T, Sripad P. Introduction of digital reporting platform to integrate community-level data into health information systems is feasible and acceptable among various community health stakeholders: a mixed-methods pilot study in Mopti Mali. J Glob Health. 2021;11:07003.

95. George AS, LeFevre AE, Schleiff M, Mancuso A, Sacks E, Sarriot E. Hubris, humility and humanity: expanding evidence approaches for improving and sustaining community health programmes. BMJ Glob Health. 2018;3:e000811

96. Schaaf M, Warthin C, Freedman L, Topp S. The community health worker as service extender, cultural broker and social change agent: a critical interpretive synthesis of roles, intent and accountability. BMJ Global Health. 2020;5:e002296.

97. Uddin M, Shams Z, Haque N, Jahan S, Perry H. Description and learnings from a pilot study to strengthen close-to-community primary health care services: the community-clinic-centered health service model in Barishal District Bangladesh. Global Health. 2021;5:88.

98. Cometto G, Ford N, Pfaffman-Zambruni J, AkI EA, Lehmann U, McPake B, Ballard M, Kok M, Najafizada M, Olaniran A, et al. Health policy and system support to optimise community health worker programmes: an abridged WHO guideline. Lancet Glob Health. 2018;6:e1397-404.

99. Everybody's Business: Strengthening Health Systems to Improve Health Outcomes. https://www.who.int/healthsystems/strategy/everybodys_ business.pdf. Accessed 11 Apr 2021

100. Sacks E, Swanson RC, Schensul JJ, Gleave A, Shelley KD, Were MK, Chowdhury AM, LeBan K, Perry HB. Community Involvement in health systems strengthening to improve global health outcomes: a review of guidelines and potential roles. Int Q Community Health Educ. 2017;37:139-49.

101. Sacks E, Morrow M, Story WT, Shelley KD, Shanklin D, Rahimtoola M, Rosales A, Ibe O, Sarriot E. Beyond the building blocks: integrating community roles into health systems frameworks to achieve health for all. BMJ Glob Health. 2018;3:e001384.

102. Harris M, Bhatti Y, Buckley J, Sharma D. Fast and frugal innovations in response to the COVID-19 pandemic. Nat Med. 2020;26:814-7.

103. Perry HB, Zulliger R, Rogers MM. Community health workers in low-, middle-, and high-income countries: an overview of their history, recent evolution, and current effectiveness. Annu Rev Public Health. 2014:35:399-421.

104. Singh P, Chokshi DA. Community health workers-a local solution to a global problem. N Engl J Med. 2013;369:894-6.

105. Fact Sheet on House's Reconciliation Package \& the Biden Administration's COVID-19 American Rescue Plan. https://welch.house.gov/sites/ welch.house.gov/files/EC\%20Reconciliation\%20Fact\%20Sheet.pdf. Accessed 11 Apr 2021

106. Public Health Job Corps: Responding to COVID-19, Rebuilding the Community Health Workforce. https://www.pih.org/sites/default/files/ 2021-02/public-health-jobs-corps-memo_05.pdf. Accessed 11 Apr 2021

107. Agarwal S, Kirk K, Sripad P, Bellows B, Abuya T, Warren C. Setting the global research agenda for community health systems: literature and consultative review. Hum Resour Health. 2019;17:22.

108. Frankel S. The community health worker: effective programmes for developing countries. Overview. Oxford: Oxford University Press; 1992.

109. Hazel E, Bryce J. IIP-JHU ICCM Evaluation Working Group: On bathwater, babies, and designing programs for impact: evaluations of the integrated community case management strategy in Burkina Faso, Ethiopia, and Malawi. Am J Trop Med Hyg. 2016;94:568-70.

110. Freeman PA, Schleiff M, Sacks E, Rassekh BM, Gupta S, Perry HB. Comprehensive review of the evidence regarding the effectiveness of 
community-based primary health care in improving maternal, neonatal and child health: 4. child health findings. J Glob Health. 2017;7:010904.

111. Chou VB, Friberg IK, Christian M, Walker N, Perry HB. Expanding the population coverage of evidence-based interventions with community health workers to save the lives of mothers and children: an analysis of potential global impact using the Lives Saved Tool (LiST). J Glob Health. 2017;7:020401.

112. Perry HB, Sacks E, Schleiff M, Kumapley R, Gupta S, Rassekh BM, Freeman PA. Comprehensive review of the evidence regarding the effectiveness of community-based primary health care in improving maternal, neonatal and child health: 6 strategies used by effective projects. J Glob Health. 2017;7:010906.

113. Oliphant NP, Manda S, Daniels K, Odendaal WA, Besada D, Kinney M, White Johansson E, Doherty T. Integrated community case management of childhood illness in low- and middle-income countries. Cochrane Database Syst Rev. 2021;2:12882

114. Perry H, Robison N, Chavez D, Taja O, Hilari C, Shanklin D, Wyon J. Attaining health for all through community partnerships: principles of the census-based, impact-oriented (CBIO) approach to primary health care developed in Bolivia South America. Soc Sci Med. 1999:48:1053-67.

115. Vasudevan L. C G, Lewin S, Henschke N, Maayan N, Eyers J, Fonhus M, Tamrat T, Mehl G: Birth and death notification via mobile devices: a mixed methods review. Cochrane Database Syst Rev. 2020;8:74.
116. Odendaal W, Anstey Watkins J, Leon N, Daniels K. Health workers' perceptions and experiences of using mHealth technologies to deliver primary health care services. Cochrane Database Syst Rev. 2020;4:987.

117. Countries must invest at least $1 \%$ more of GDP on primary health care to eliminate glaring coverage gaps. https://www.who.int/news-room/ detail/22-09-2019-countries-must-invest-at-least-1-more-of-gdp-onprimary-health-care-to-eliminate-glaring-coverage-gaps. Accessed 11 Apr 2021

118. Gichaga A, Masis L, Chandra A, Palazuelos D, Wakaba N. Mind the global community health funding gap. Glob Health Sci Pract. 2021;9:S9-17.

119. Sherry M, Ghaffar A, Bishai D. Community platforms for health inferventions. In: Jamison D, Gelband H, Horton S, Jha P, Laxminarayan R, Mock C, Nugent R, editors. Disease control priorities: improving health and reducing poverty. Washington: The World Bank; 2018. p. 267-83.

120. Covid-19: Community health workers as first line of defence. https:// tbsnews.net/thoughts/covid-19-community-health-workers-first-linedefence-102379. Accessed 11 Apr 2021

\section{Publisher's Note}

Springer Nature remains neutral with regard to jurisdictional claims in published maps and institutional affiliations.
Ready to submit your research? Choose BMC and benefit from:

- fast, convenient online submission

- thorough peer review by experienced researchers in your field

- rapid publication on acceptance

- support for research data, including large and complex data types

- gold Open Access which fosters wider collaboration and increased citations

- maximum visibility for your research: over $100 \mathrm{M}$ website views per year

At BMC, research is always in progress.

Learn more biomedcentral.com/submissions 